\title{
Synthesis, Crystal Structure, and Antimicrobial Properties of a Novel 1-D Cobalt Coordination Polymer with Dicyanamide and 2-Aminopyridine
}

\author{
Amah Colette Benedicta Yuoh, ${ }^{1}$ Moise Ondoh Agwara, ${ }^{1}$ Divine Mbom Yufanyi, ${ }^{2}$ \\ Mariam Aseng Conde, ${ }^{3}$ Rajamony Jagan, ${ }^{4}$ and Kenneth Oben Eyong ${ }^{5}$ \\ ${ }^{1}$ Department of Inorganic Chemistry, Faculty of Science, University of Yaoundé I, P.O. Box 812, Yaoundé, Cameroon \\ ${ }^{2}$ Department of Chemistry, Faculty of Science, The University of Bamenda, P.O. Box 39, Bambili, Bamenda, Cameroon \\ ${ }^{3}$ Département de Chimie, Faculté des Sciences, Université de Douala, Douala, Cameroon \\ ${ }^{4}$ Sophisticated Analytical Instruments Facility, Indian Institute of Technology, Madras, Chennai 600036, India \\ ${ }^{5}$ Department of Organic Chemistry, Faculty of Science, University of Yaoundé I, P.O. Box 812, Yaoundé, Cameroon
}

Correspondence should be addressed to Moise Ondoh Agwara; agwara29@yahoo.com

Received 6 April 2015; Revised 4 June 2015; Accepted 7 June 2015

Academic Editor: Alfonso Castiñeiras

Copyright (C) 2015 Amah Colette Benedicta Yuoh et al. This is an open access article distributed under the Creative Commons Attribution License, which permits unrestricted use, distribution, and reproduction in any medium, provided the original work is properly cited.

\begin{abstract}
A novel one-dimensional coordination polymer bis(2-aminopyridine)- $\mu$-bis(dicyanamido) cobaltate(II) has been synthesized and characterized by elemental analyses and infrared and ultraviolet visible spectroscopies and the structure has been determined by single crystal X-ray diffraction. Co(II) ion in the complex is coordinated to two axial 2-aminopyridine ligands through the pyridine $\mathrm{N}$-atom and four equatorial dicyanamide ligands to give a $\mathrm{CoN}_{6}$ slightly distorted octahedral coordination environment around the metal ion. The amino $\mathrm{N}$-atom forms intrachain hydrogen bonds. Antimicrobial screening of the complex against eight pathogenic microorganisms (four bacteria and four fungi) isolated from humans, indicates that the complex is moderately active.
\end{abstract}

\section{Introduction}

Transition metal complexes of N-donor heterocyclic ligands are of interest due to their applications in biology, pharmacology, magnetism, and so forth [1]. Pyridine and its derivatives are known for their use in the design and synthesis of multifunctional compounds as well as their biological and pharmacological applications as anticoagulants, antihistamines, antiseptics, antiarrhythmics, and antirheumatics [2$4]$. Amongst the pyridine derivatives, 2-aminopyridine (2ampy), a potential bidentate ligand with two nitrogen donor atoms, is of great pharmacological importance because it is used in the synthesis of pharmaceuticals such as antihistamines and anti-inflammatories [5]. 2-ampy has also been shown to have a major influence on the formation of transition metal molybdates in which it acts as a buffer and forms weaker complexes with the transition metals, thus preventing their hydrolysis [6]. A survey of the reported crystal structures of 2-ampy with different metal ions indicates that 2-ampy exhibits different bonding modes: it mostly acts as a monodentate ligand through its pyridine nitrogen atom $[4,7-11]$, though coordination through the exocyclic amino $\mathrm{N}$-atom (a less common mode) has also been reported $[12,13]$. When it coordinates through the pyridine $\mathrm{N}$-atom, the formation of additional H-bonds through the exocyclic amine $\mathrm{N}$-atom is possible [14]. It also forms chelates with a bidentate coordination mode through the pyridine $\mathrm{N}$ and exocyclic amine $\mathrm{N}$ atoms [15]. Several mixed ligand complexes containing 2-ampy have also been synthesized with different properties and diverse applications $[7,9-12,16-$ 25].

Dicyanamide (dca) has been used extensively as a building block in supramolecular chemistry and crystal engineering [26]. This pseudohalide shows versatility in its coordination modes; it can act as a monodentate ligand through 
nitrile nitrogen, as a bidentate ligand through terminal nitrile nitrogen atoms, or as a bridging ligand in varied bridging modes [26-31]. The versatile coordination ability of dca has led to the design and synthesis of several metal-dicyanamide complexes with varied topologies and magnetic properties $[26,27]$.

The chemistry of cobalt(II) complexes with $\mathrm{O}$ - and $\mathrm{N}$ donor ligands has been extensively studied and it was found to have diverse properties $[1,7,20,30,32]$. Some of the complexes have been shown to possess antitumor properties [33], as well as antimicrobial activity against resistant microbial strains $[12,34,35]$.

The increased resistance of microorganisms to antimicrobial agents imposes the search for alternative and more potent agents. The improved biological activity of several transition metal complexes upon coordination to different $\mathrm{N}$-containing heterocyclic ligands reported has caused the design and synthesis of these complexes $[33,36]$.

In view of the varied applications of cobalt mixed ligand complexes and exploring the good biological properties of cobalt and 2-ampy as well as the structure-directing properties of dca, we report herein the crystal structure of a novel cobalt(II) coordination polymer containing 2-ampy and dca. The biological activity of the complex towards some resistant pathogens, evaluated using in vitro assays, is also presented.

\section{Experimental}

2.1. Materials and Method. All chemicals and solvents were obtained from commercial sources and used as received.

2.2. Synthesis of the Complex. $10 \mathrm{~mL}$ ethanol/water $(1: 1)$ solution of sodium dicyanamide and $\mathrm{NaC}_{2} \mathrm{~N}_{3}(0.36 \mathrm{~g} ; 4 \mathrm{mmol})$ were added dropwise to a stirred ethanolic solution $(10 \mathrm{~mL})$ of cobalt nitrate hexahydrate and $\mathrm{Co}\left(\mathrm{NO}_{3}\right)_{2} \cdot 6 \mathrm{H}_{2} \mathrm{O}(0.59 \mathrm{~g}$; $2 \mathrm{mmol}$ ) at room temperature. The resulting pink mixture was stirred for $30 \mathrm{~min}$ after which an ethanolic solution $(10 \mathrm{~mL})$ of 2 -aminopyridine $(0.77 \mathrm{~g} ; 8 \mathrm{mmol})$ was added dropwise. The resulting mixture was further stirred for $1 \mathrm{~h}$ after which a pink precipitate was afforded. The precipitate was filtered, washed with distilled water, air-dried, and weighed (yield 53\%). The filtrate was allowed to evaporate at room temperature and pink crystals were obtained. [Co(2-ampy $\left.)_{2}(\mathrm{dca})_{2}\right]$ : yield: $53 \%$. Pink, m.p.: $246^{\circ}$ C. Element Anal. Calc. for $\mathrm{CoC}_{14} \mathrm{H}_{14} \mathrm{~N}_{10}$ : C, 44.10; H, 3.70; N, 36.74. Found: C, 44.00; H, 3.68; N, 36.84. FTIR $\left(\mathrm{cm}^{-1}\right): 3478\left(\nu_{\mathrm{N}-\mathrm{H}}\right), 2241$ and $1489\left(\nu_{\mathrm{C} \equiv \mathrm{N}}\right), 1329\left(\nu_{\mathrm{CN}}\right)$, and 434 and $560\left(\nu_{\mathrm{M}-\mathrm{N}}\right)$.

2.3. Characterization Techniques. The melting point temperature was recorded using the Leica VMHB Kofler system. Conductivity measurement was carried out in distilled water using a CD810 Tacussel Electronic Conductometer at room temperature. Elemental analysis $(\mathrm{C}, \mathrm{H}, \mathrm{N})$ was carried out on a Flash 2000 Thermo Scientific analyzer. The infrared spectrum was recorded using a Bruker ALPHA-P spectrophotometer directly on a small sample of the complex in the range $400-4000 \mathrm{~cm}^{-1}$ while the UV-visible spectrum of an ethanolic solution of the complex was recorded using a Bruker HACH DR 3900 UV-Visible spectrophotometer at room temperature.

2.4. Single Crystal X-Ray Structure Determination. Intensity data for the compound was collected using a Bruker AXS Kappa APEX II single crystal CCD Diffractometer, equipped with graphite-monochromated $\mathrm{MoK} \alpha$ radiation $(\lambda=0.71073 \AA)$ at room temperature. The selected crystal for the diffraction experiment had a dimension of $0.25 \times$ $0.25 \times 0.2 \mathrm{~mm}^{3}$. Accurate unit cell parameters were determined from the reflections of 36 frames measured in three different crystallographic zones by the method of difference vectors. The data collection, data reduction, and absorption correction were performed by APEX2, SAINT-Plus, and SADABS programs [37]. The structure was solved by direct methods procedure using SHELXS-97 program [38] and the nonhydrogen atoms were subjected to anisotropic refinement by full-matrix least squares on $F^{2}$ using SHELXL97 program [38]. The positions of all the hydrogen atoms were identified from difference electron density map and were fixed accordingly. All the aromatic hydrogen atoms were constrained to ride on the corresponding nonhydrogen atoms with a distance of $\mathrm{C}-\mathrm{H}=0.93 \AA$ and $\mathrm{U}_{\text {iso }}(\mathrm{H})=1.2 \mathrm{U}_{\text {eq }}(\mathrm{C})$ whereas the hydrogen atoms associated with all the $\mathrm{N}$ atoms were restrained to a distance of $\mathrm{N}-\mathrm{H}=0.88(2) \AA$.

2.5. Antimicrobial Tests. The antimicrobial tests were carried out in the laboratory of Phytobiochemical and Medicinal Plant Study, University of Yaoundé I. The tests were done on eight pathogenic microorganisms, 4 yeasts, Candida albicans ATCC P37039, Candida albicans 194B, Candida glabrata 44B, and Cryptococcus neoformans and 4 bacterial strains, Gram-positive Staphylococcus aureus CIP 7625 and Gramnegatives, Pseudomonas aeruginosa CIP 76110, Salmonella typhi, and Escherichia coli ATCC 25922 obtained from Centre Pasteur, Yaoundé, Cameroon. Reference antibacterial drug chloramphenicol and antifungal drug nystatin were evaluated for their antibacterial and antifungal activities and their results were compared with those of the free ligands and the complex.

The disk diffusion method, using Muller Hinton Agar, from the protocol described by the National Committee for Clinical Laboratory Standard (NCCLS, 2004) was used for preliminary screening.

Mueller-Hinton agar was prepared from a commercially available dehydrated base according to the manufacturer's instructions. Several colonies of each microorganism were collected and suspended in saline $(0.9 \% \mathrm{NaCl})$. Then, the turbidity of the test suspension was standardized to match that of a $0.5 \mathrm{McF}$ arland standard (corresponds to approximately $1.5 \times 10^{8} \mathrm{CFU} / \mathrm{mL}$ for bacteria or $1 \times 10^{6}$ to $5 \times$ $10^{6}$ cells $/ \mathrm{mL}$ for yeast). Each compound or reference was accurately weighed and dissolved in the appropriate diluents (DMSO at $10 \%$, methanol at $10 \%$, or distilled water) to yield the required concentration $(2 \mathrm{mg} / \mathrm{mL}$ for compound or $1 \mathrm{mg} / \mathrm{mL}$ for reference drug), using sterile glassware. 
Whatman filter paper number 1 was used to prepare disks approximately $6 \mathrm{~mm}$ in diameter, which were packed up with aluminum paper and sterilized by autoclaving. Then, $25 \mu \mathrm{L}$ of stock solutions of compound or positive control were delivered to each disk, leading to $50 \mu \mathrm{g}$ of compound or $25 \mu \mathrm{g}$ of reference drug.

The dried surface of a Müller-Hinton agar plate was inoculated by flooding over the entire sterile agar surface with $500 \mu \mathrm{L}$ of inoculum suspensions. The lid was left ajar for 3 to 5 minutes to allow for any excess surface moisture to be absorbed before applying the drug impregnated disks. Disks containing the compounds or antimicrobial agents were applied within 15 minutes of inoculating the MHA plate. Six disks per petri dish were plated. The plates were inverted and placed in an incubator set to $35^{\circ} \mathrm{C}$. After 18 hours (for bacteria) and 24 hours (for yeasts) of incubation, each plate was examined. The diameters of the zones of complete inhibition (as judged by the unaided eye) were measured, including the diameter of the disk. Zones were measured to the nearest whole millimeter, using sliding calipers, which were held on the back of the inverted petri plate. All experiments were carried out in duplicate. The compound was considered active against a microbe if the inhibition zone was $6 \mathrm{~mm}$ and above.

\section{Results and Discussion}

3.1. Synthesis of the Complex. The title complex is pink and air stable with a sharp melting point $\left(246^{\circ} \mathrm{C}\right)$ indicating its purity. The molar conductivity value of the complex is $67.5 \Omega \mathrm{cm}^{-2} \mathrm{~mol}^{-1}$ in water, indicating that it is a nonelectrolyte.

3.2. X-Ray Crystal Structure. The ORTEP view of the crystal structure of bis(2-aminopyridine)- $\mu$-bis(dicyanamido) cobaltate(II), $\left[\mathrm{Co}(2 \text {-ampy })_{2}(\mathrm{dca})_{2}\right]$ together with the atom numbering scheme used in the corresponding tables is shown in Figure 1 . The crystal packing diagram for $[\mathrm{Co}(2-$ ampy $)_{2}(\mathrm{dca})_{2}$ ] seen along the crystallographic $a$-axes is shown in Figure 2 and the 1-D polymeric chain structure of the complex is shown in Figure 3. The crystal data is presented in Table 1, while the selected bond lengths and bond angles are shown in Table 2.

The complex crystallizes in the monoclinic crystal system with space group $\mathrm{P} 2 / \mathrm{c}$. The asymmetric unit consists of one 2 -ampy molecule, one dicyanamide anion, and one Co(II) ion. The crystal structure shows that Col adopts a slightly distorted octahedral environment $\left(\mathrm{CoN}_{6}\right)$ in which it is covalently bonded to two pyridine $\mathrm{N}$-atoms (Co-N1 2.193(3) $\AA$ ) arranged axially and four nitrile $\mathrm{N}$-atoms (Col-N3 2.126(2) $\AA$ and Col-N5 2.128(2) $\AA$ ) from four dca anions in equatorial positions. The Col-N1 bond length is slightly longer than that reported for other cobalt complexes wih 2-ampy $[4,7,9,20]$. The Col-N3 (2.126 $\AA$ ) and Co1-N5 (2.128 $\AA$ ) bond lengths are similar to values reported in the literature for other $\mathrm{Co}-\mathrm{N}$ bonds with nitrile $\mathrm{N}[26,30]$. The dca ligand adopts a bridging coordination mode through the terminal nitrile $\mathrm{N}$-atoms. In the equatorial plane, the bonding configuration of dca around
TABle 1: Crystal data and structure refinement for $[\mathrm{Co}(2-$ ampy $\left.)_{2}(\mathrm{dca})_{2}\right]$.

\begin{tabular}{|c|c|}
\hline Empirical formula & $\mathrm{C}_{14} \mathrm{H}_{14} \mathrm{CoN}_{10}$ \\
\hline Formula weight & 381.28 \\
\hline Temperature & 293(2) K \\
\hline Wavelength & $0.71073 \AA$ \\
\hline Crystal system & Monoclinic \\
\hline Space group & $\mathrm{P} 2_{1} / \mathrm{c}$ \\
\hline \multirow{6}{*}{ Unit cell dimensions } & $a=7.4488(4) \AA$ \\
\hline & $b=14.8145(8) \AA$ \\
\hline & $c=7.3934(4) \AA$ \\
\hline & $\alpha=90^{\circ}$ \\
\hline & $\beta=102.016(3)^{\circ}$ \\
\hline & $\gamma=90^{\circ}$ \\
\hline Volume & $797.99(7) \AA^{3}$ \\
\hline$Z$ & 2 \\
\hline Density (calculated) & $1.587 \mathrm{mg} / \mathrm{m}^{3}$ \\
\hline Absorption coefficient & $1.097 \mathrm{~mm}^{-1}$ \\
\hline$F(000)$ & 390 \\
\hline Crystal size & $0.25 \times 0.25 \times 0.20 \mathrm{~mm}$ \\
\hline Theta range for data collection & 2.75 to $27.47^{\circ}$ \\
\hline Limiting indices & $-9 \leq h \leq 9,-19 \leq k \leq 19,-9 \leq l \leq 9$ \\
\hline Reflections collected/unique & $14670 / 1813[R($ int $)=0.0543]$ \\
\hline Completeness to theta & $27.47 \quad 99.0 \%$ \\
\hline Absorption correction & Semiempirical from equivalents \\
\hline Max. and min. transmission & 0.8105 and 0.7711 \\
\hline Refinement method & Full-matrix least-squares on $F^{2}$ \\
\hline Data/restraints/parameters & $1813 / 44 / 145$ \\
\hline Goodness-of-fit on $F^{2}$ & 1.102 \\
\hline Final $R$ indices $[I>2 \operatorname{sigma}(I)]$ & $R 1=0.0432, w R 2=0.1142$ \\
\hline$R$ indices (all data) & $R 1=0.0568, w R 2=0.1258$ \\
\hline
\end{tabular}

the $\mathrm{Col}$ atoms is nonlinear as evidenced by the bond angles C6-N3-Col $\left(164.9^{\circ}\right)$ and C7-N5-Col $\left(157.7^{\circ}\right)$. This observation is consistent with the literature reports [30]. Each Col atom is linked to two Col atoms through two $1,5-\mu_{2}$-dca bridges resulting in a 1-D polymeric chain structure (Figure 3 ). There are no intermolecular hydrogen bonds in the complex but only intrachain $\mathrm{H}$-bonds between the exocyclic amino group and dca nitrogen atom $(\mathrm{N} 2-\mathrm{H} \cdots \mathrm{N} 3)$ and that between $\mathrm{N}$ -

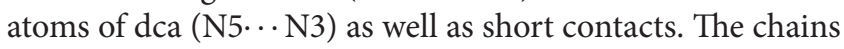
are held together by these short contacts.

3.3. IR Spectroscopy. The relevant IR bands are summarized in Table 3. In the spectrum of 2-ampy, the absorption bands at 3478 and $3287 \mathrm{~cm}^{-1}$ in the ligand assigned to $\nu_{\text {as }(\mathrm{N}-\mathrm{H})}$ and $v_{\mathrm{s}(\mathrm{N}-\mathrm{H})}$, respectively, are not shifted in the complex indicating that the amino $\mathrm{N}$-atom is not participating in bonding [4]. This observation is consistent with the X-ray crystal structure that shows coordination of the 2-ampy ligand only through the pyridine $\mathrm{N}$-atom. The sharp vibration band at $1557 \mathrm{~cm}^{-1}$ attributed to $v_{\mathrm{C}=\mathrm{N}}$ of 2 -ampy has been shifted to $1549 \mathrm{~cm}^{-1}$ in the complex, indicating its participation in bonding [7]. The spectra of the dca ligand and the complex 


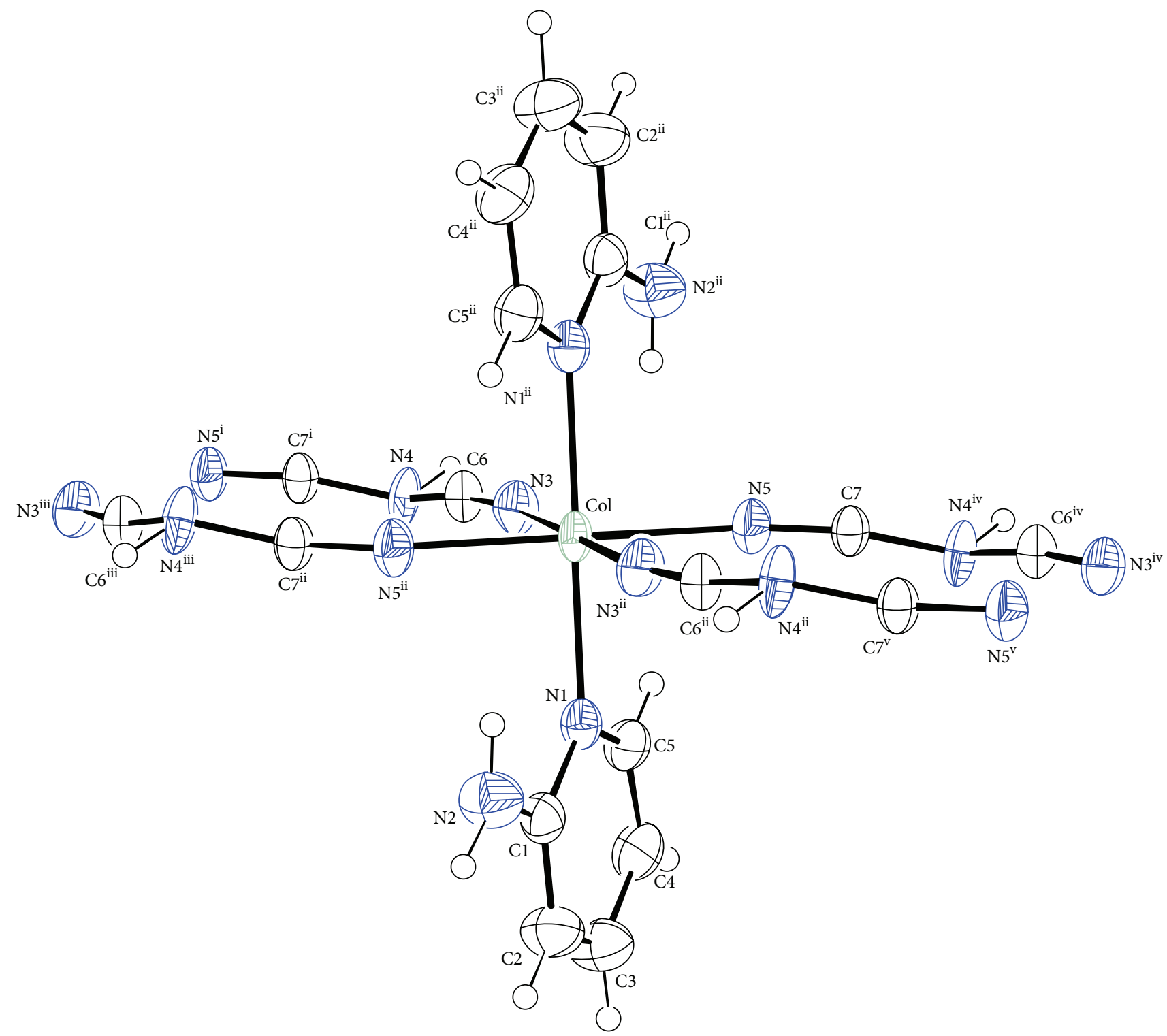

FIgURE 1: ORTEP view of the complex $\left[\mathrm{Co}(2 \text {-ampy })_{2}(\mathrm{dca})_{2}\right]$ together with the numbering scheme.

show strong absorption bands in the $2310-2100 \mathrm{~cm}^{-1}$ region attributed to the $v_{\mathrm{s}}+v_{\mathrm{as}}(\mathrm{C} \equiv \mathrm{N}), v_{\mathrm{as}}(\mathrm{C} \equiv \mathrm{N})$, and $\nu_{\mathrm{s}}(\mathrm{C} \equiv \mathrm{N})$ vibrational modes of dca $[27,30]$. The appearance of two new characteristic bands, $434 \mathrm{~cm}^{-1}$ and $560 \mathrm{~cm}^{-1}$ in the spectrum of the complex, which were not found in the spectra of the ligands, indicates the presence of $\mathrm{M}-\mathrm{N}$ bonding between the metal and the nitrogen atoms of both 2-aminopyridine and dca. This observation is confirmed by the X-ray structure of the complex which shows that cobalt is bonded to both 2ampy and dca through $\mathrm{N}$-atoms.

3.4. UV-Visible Spectroscopy. In octahedral symmetry, sixcoordinate high-spin cobalt(II) exhibits three spin-allowed electronic transitions assigned as ${ }^{4} \mathrm{~T}_{1 \mathrm{~g}}(\mathrm{~F}) \rightarrow{ }^{4} \mathrm{~T}_{2 \mathrm{~g}},{ }^{4} \mathrm{~T}_{1 \mathrm{~g}}(\mathrm{~F})$ $\rightarrow{ }^{4} \mathrm{~A}_{2 \mathrm{~g}}$ and ${ }^{4} \mathrm{~T}_{1 \mathrm{~g}}(\mathrm{~F}) \rightarrow{ }^{4} \mathrm{~T}_{1 \mathrm{~g}}(\mathrm{P})$ [27]. The UV-vis spectrum of the title compound reveals two (d-d) absorption bands at $498 \mathrm{~nm}$ and $642 \mathrm{~nm}$ which correspond to ${ }^{4} \mathrm{~T}_{1 \mathrm{~g}}(\mathrm{~F}) \rightarrow{ }^{4} \mathrm{~T}_{2 \mathrm{~g}}$ and ${ }^{4} \mathrm{~T}_{1 \mathrm{~g}}(\mathrm{~F}) \rightarrow{ }^{4} \mathrm{~T}_{1 \mathrm{~g}}(\mathrm{P})$ transitions, respectively [27]. This discloses octahedral geometry. The band at $427 \mathrm{~nm}$ is masked by the broad band at $498 \mathrm{~nm}$. This observation is consistent with octahedral geometry around the Co(II) center and this is confirmed by the X-ray structure of the complex. In octahedral symmetry, six-coordinate high-spin cobalt(II) exhibits three spin-allowed electronic transitions assigned as ${ }^{4} \mathrm{~T}_{1 \mathrm{~g}}(\mathrm{~F}) \rightarrow{ }^{4} \mathrm{~T}_{2 \mathrm{~g}},{ }^{4} \mathrm{~T}_{1 \mathrm{~g}}(\mathrm{~F}) \rightarrow{ }^{4} \mathrm{~A}_{2 \mathrm{~g}}$, and ${ }^{4} \mathrm{~T}_{1 \mathrm{~g}}(\mathrm{~F}) \rightarrow{ }^{4} \mathrm{~T}_{1 \mathrm{~g}}(\mathrm{P})$ [27].

3.5. Antimicrobial Tests. The potency of the metal salt, 2aminopyridine, dca, and the complex together with the reference antibacterial drug (chloramphenicol) and antifungal 


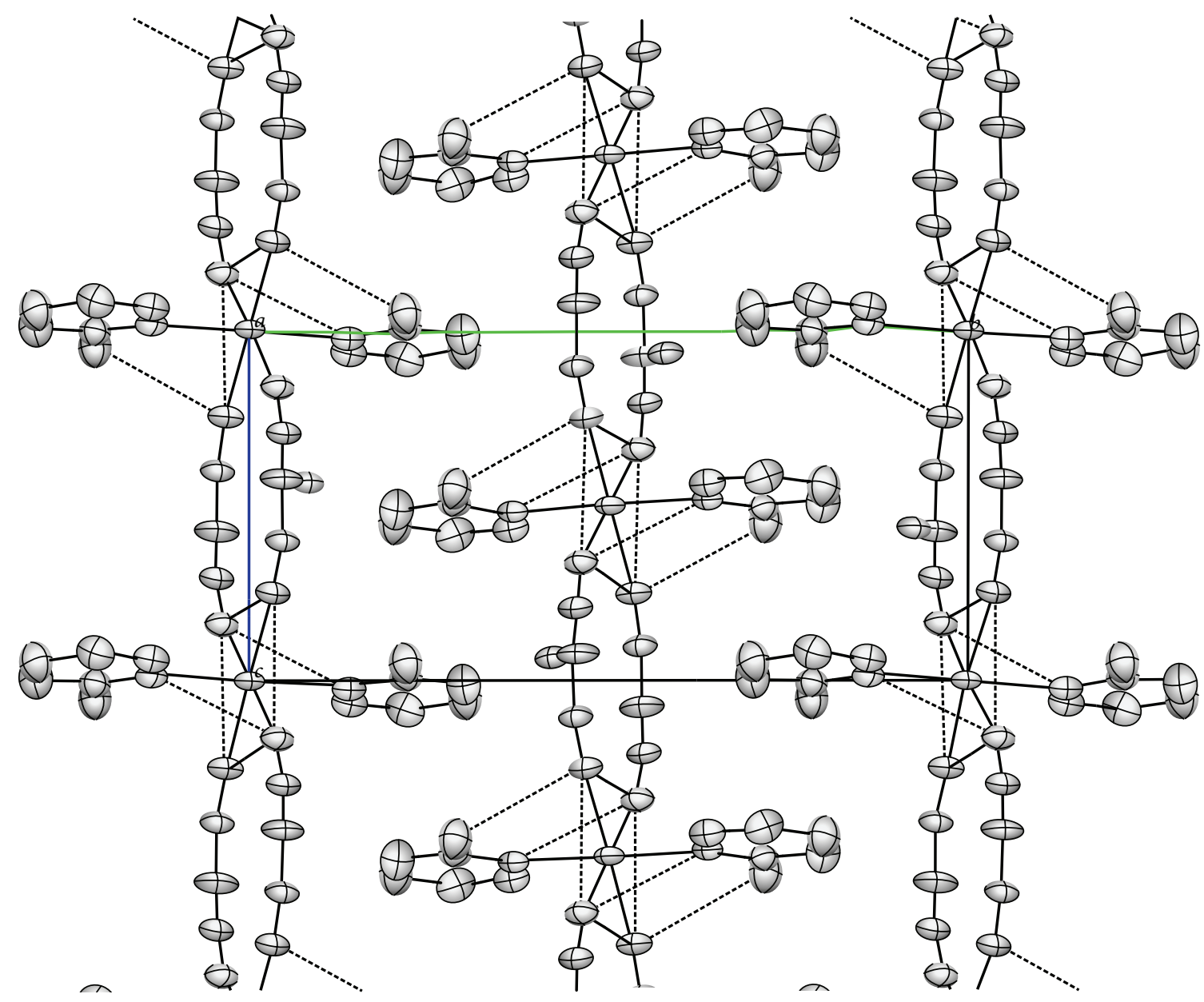

FIGURE 2: Packing diagram of the complex showing hydrogen bonding scheme.

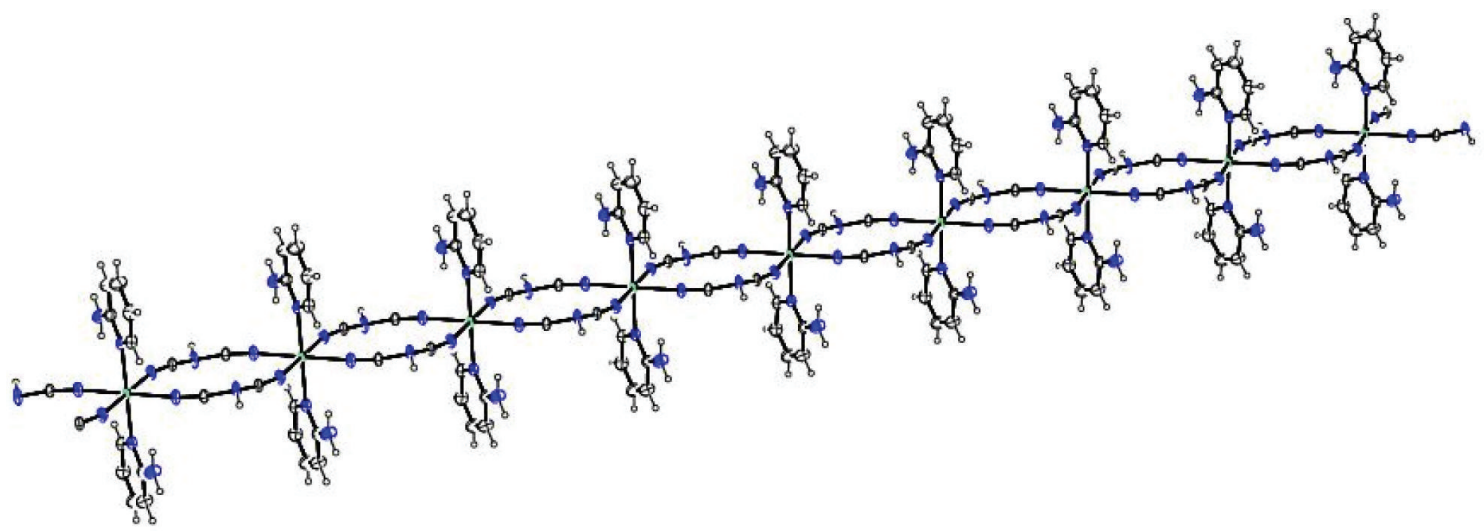

FIGURE 3: 1-D polymeric chain structure of the complex.

drug (nystatin) was evaluated against four bacteria and four fungi strains. The results of the preliminary screening obtained are presented in Table 4.

The results indicate that dca exhibits the highest activity against the pathogens, especially against the fungi species, followed by the metal salt with a generally high activity against the pathogens. The ligand 2-aminopyridine shows a relatively low activity against both fungi and bacteria species. The metal complex shows moderate activity compared to that of the free ligands. The complex is most active against the fungi C. albicans 194B, C. glabrata $44 \mathrm{~B}$ and the bacteria species $P$. aeruginosa and $S$. typhi. The activity of the complex towards 
TABLE 2: Selected bond lengths $[\AA]$ and angles $\left[{ }^{\circ}\right]$ for $\left[\mathrm{Co}(2 \text {-ampy })_{2}(\mathrm{dca})_{2}\right]$.

\begin{tabular}{|c|c|c|c|}
\hline $\mathrm{Co}(1)-\mathrm{N}(3)$ & $2.126(2)$ & $\mathrm{N}(3)-\mathrm{Co}(1)-\mathrm{N}(3) \# 1$ & 180.0 \\
\hline $\mathrm{Co}(1)-\mathrm{N}(3) \# 1$ & $2.126(2)$ & $\mathrm{N}(3)-\mathrm{Co}(1)-\mathrm{N}(5)$ & $92.28(10)$ \\
\hline $\mathrm{Co}(1)-\mathrm{N}(5)$ & $2.128(2)$ & $\mathrm{N}(3) \# 1-\mathrm{Co}(1)-\mathrm{N}(5)$ & $87.72(10)$ \\
\hline $\mathrm{Co}(1)-\mathrm{N}(5) \# 1$ & $2.128(2)$ & $\mathrm{N}(3)-\mathrm{Co}(1)-\mathrm{N}(5) \# 1$ & $87.72(10)$ \\
\hline $\mathrm{Co}(1)-\mathrm{N}(1) \# 1$ & $2.193(3)$ & $\mathrm{N}(3) \# 1-\mathrm{Co}(1)-\mathrm{N}(5) \# 1$ & $92.28(10)$ \\
\hline $\mathrm{Co}(1)-\mathrm{N}(1)$ & $2.193(3)$ & $\mathrm{N}(5)-\mathrm{Co}(1)-\mathrm{N}(5) \# 1$ & $180.00(9)$ \\
\hline $\mathrm{N}(1)-\mathrm{C}(1)$ & $1.342(4)$ & $\mathrm{N}(3)-\mathrm{Co}(1)-\mathrm{N}(1) \# 1$ & $91.68(10)$ \\
\hline $\mathrm{N}(1)-\mathrm{C}(5)$ & $1.350(4)$ & $\mathrm{N}(3) \# 1-\mathrm{Co}(1)-\mathrm{N}(1) \# 1$ & $88.32(10)$ \\
\hline $\mathrm{N}(5)-\mathrm{C}(7)$ & $1.134(3)$ & $\mathrm{N}(5)-\mathrm{Co}(1)-\mathrm{N}(1) \# 1$ & $92.02(10)$ \\
\hline $\mathrm{N}(2)-\mathrm{C}(1)$ & $1.360(4)$ & $\mathrm{N}(5) \# 1-\mathrm{Co}(1)-\mathrm{N}(1) \# 1$ & $87.98(10)$ \\
\hline $\mathrm{C}(5)-\mathrm{C}(4)$ & $1.364(5)$ & $\mathrm{N}(3)-\mathrm{Co}(1)-\mathrm{N}(1)$ & $88.32(10)$ \\
\hline$C(3)-C(2)$ & $1.358(6)$ & $\mathrm{N}(3) \# 1-\mathrm{Co}(1)-\mathrm{N}(1)$ & $91.68(10)$ \\
\hline $\mathrm{C}(1)-\mathrm{C}(2)$ & $1.391(5)$ & $\mathrm{N}(5)-\mathrm{Co}(1)-\mathrm{N}(1)$ & $87.98(10)$ \\
\hline $\mathrm{C}(7)-\mathrm{N}(4) \# 2$ & $1.305(15)$ & $\mathrm{N}(5) \# 1-\mathrm{Co}(1)-\mathrm{N}(1)$ & $92.02(10)$ \\
\hline $\mathrm{C}(7)-\mathrm{N}\left(4^{\prime}\right) \# 2$ & $1.313(14)$ & $\mathrm{N}(1) \# 1-\mathrm{Co}(1)-\mathrm{N}(1)$ & $180.00(13)$ \\
\hline$N(3)-C(6)$ & $1.127(6)$ & $\mathrm{C}(1)-\mathrm{N}(1)-\mathrm{C}(5)$ & $116.8(3)$ \\
\hline $\mathrm{N}(3)-\mathrm{C}\left(6^{\prime}\right)$ & $1.129(6)$ & $\mathrm{C}(1)-\mathrm{N}(1)-\mathrm{Co}(1)$ & $128.3(2)$ \\
\hline $\mathrm{N}(4)-\mathrm{C}(7) \# 3$ & $1.305(15)$ & $\mathrm{C}(5)-\mathrm{N}(1)-\mathrm{Co}(1)$ & $114.9(2)$ \\
\hline$N(4)-C(6)$ & $1.324(18)$ & $\mathrm{C}(7)-\mathrm{N}(5)-\mathrm{Co}(1)$ & $157.7(2)$ \\
\hline $\mathrm{N}\left(4^{\prime}\right)-\mathrm{C}\left(6^{\prime}\right)$ & $1.310(14)$ & $N(1)-C(5)-C(4)$ & $124.1(3)$ \\
\hline $\mathrm{N}\left(4^{\prime}\right)-\mathrm{C}(7) \# 3$ & $1.314(14)$ & $\mathrm{N}(1)-\mathrm{C}(1)-\mathrm{N}(2)$ & $118.3(3)$ \\
\hline$C(3)-C(2)$ & $1.358(6)$ & $\mathrm{N}(1)-\mathrm{C}(1)-\mathrm{C}(2)$ & $121.9(3)$ \\
\hline \multirow[t]{2}{*}{$C(1)-C(2)$} & $1.391(5)$ & $N(2)-C(1)-C(2)$ & $119.8(3)$ \\
\hline & & $C(3)-C(2)-C(1)$ & $119.9(4)$ \\
\hline
\end{tabular}

Symmetry transformations used to generate equivalent atoms: $\# 1:-x,-y,-z+2$; \#2: $x, y, z-1 ; \# 3: x, y, z+1$.

TABLE 3: Relevant IR bands of the ligands and complex.

\begin{tabular}{lccccc}
\hline Compounds & $\nu_{(\mathrm{N}-\mathrm{H})} \mathrm{cm}^{-1}$ & $\nu_{(\mathrm{C} \equiv \mathrm{N})} \mathrm{cm}^{-1}$ & $\nu_{(\mathrm{C}=\mathrm{N})} \mathrm{cm}^{-1}$ & $\nu_{(\mathrm{C}-\mathrm{N})} \mathrm{cm}^{-1}$ & 1440 \\
\hline 2-ampy & 3287 & $/$ & 1557 & 1 & 1338 \\
dca & $/$ & 2226 & $/$ & 1 & 1 \\
Co(2-ampy $)_{2}(\mathrm{dca})_{2}$ & 3478 & 2241 & 1489 & 1329 & 434 \\
& & & & 560 \\
\hline
\end{tabular}

TABLE 4: Diameter of zone of inhibition of the complex, ligands, and the metal salt.

\begin{tabular}{|c|c|c|c|c|c|c|c|}
\hline & \multirow{2}{*}{ Species } & \multicolumn{6}{|c|}{ Zone of inhibition $(\mathrm{mm})$} \\
\hline & & $\mathrm{Co}\left(\mathrm{NO}_{3}\right)_{2}$ & $\mathrm{dca}$ & 2-ampy & $\mathrm{Co}(2 \text {-ampy })_{2}(\mathrm{dca})_{2}$ & Chloramphenicol & Nystatin \\
\hline \multirow{4}{*}{ Fungi } & C. albicans ATCC P37039 & 8.5 & 11.5 & 6.0 & 6.0 & 7.5 & 6.0 \\
\hline & C. albicans 194B & 6.0 & 7.5 & 7.0 & 9.0 & 14.5 & 7.0 \\
\hline & C. glabrata 44B & 7.5 & 14.0 & 6.0 & 8.0 & 6.0 & 6.0 \\
\hline & C. neoformans & 8.0 & 11.5 & 6.0 & 7.0 & 10.5 & 9.5 \\
\hline \multirow{4}{*}{ Bacteria } & E. coli & 7.0 & 9.0 & 8.0 & 6.0 & 12.0 & 6.0 \\
\hline & $P$. aeruginosa & 11.5 & 6.0 & 6.0 & 8.5 & 11.5 & 6.0 \\
\hline & S. typhi & 11.0 & 6.0 & 8.0 & 8.5 & 10.0 & 6.0 \\
\hline & S. aureus & 10.0 & 6.0 & 6.0 & 6.0 & 14.0 & 10.5 \\
\hline
\end{tabular}

the microorganisms decreases in the order C. albicans 194B > $P$. aeruginosa $=S$. typhi $>$ C. glabrata $44 \mathrm{~B}>$ C. neoformans $>$ E. coli. It shows greater activity towards the fungi than the bacteria species and their activities are comparable to those of the reference drugs used. The complex is also more active than the reference drug nystatin towards the fungi species. This indicates that reaction of metal ions with the ligand plays an important role in enhancing its antimicrobial activity. This increase in activity could be due to the reduction of the polarity of the metal ion by partial sharing of 
the positive charge with the ligand's donor atoms so that there is electron delocalization within the metal complex. This may increase the hydrophobic and lipophilic character of the metal complex, enabling it to permeate the lipid layer of the organism killing them more effectively $[39,40]$.

\section{Conclusion}

The synthesis of a novel mixed ligand Co(II) 1-D polymer with 2 -aminopyridine and dca has been reported. The equatorial and terminal bridging dca ligands coordinate in a nonlinear manner to the central metal ion while the axial 2-ampy ligands coordinate to the $\mathrm{Co}$ (II) ion through the pyridine $\mathrm{N}$-atoms. The $\mathrm{Co}(\mathrm{II})$ ion in the complex adopts a slightly distorted octahedral environment comprising two pyridine $\mathrm{N}$-atoms from 2-aminopyridine and four nitrile $\mathrm{N}$-atoms from the dicyanamide. The amino $\mathrm{N}$-atoms are involved in intrachain hydrogen bonds. The results of the preliminary antimicrobial screening against four pathogenic bacteria and four fungi species indicate that the complex is moderately active and could be further screened in vitro against a wide range of pathogens.

\section{Supporting Information}

CCDC 1007918 contains the supplementary crystallographic data for the complex. The data can be obtained free of charge from The Cambridge Crystallographic Data Centre via https://www.ccdc.cam.ac.uk/data_request/cif.

\section{Conflict of Interests}

The authors declare that there is no conflict of interests regarding the publication of this paper.

\section{Acknowledgment}

Moise Ondoh Agwara, Divine Mbom Yufanyi, Mariam Aseng Conde, and Kenneth Oben Eyong thank the Government of Cameroon for financial support through the Fonds d'Appuis à la Recherche.

\section{References}

[1] C. V. Sastri, D. Eswaramoorthy, L. Giribabu, and B. G. Maiya, "DNA interactions of new mixed-ligand complexes of cobalt(III) and nickel(II) that incorporate modified phenanthroline ligands," Journal of Inorganic Biochemistry, vol. 94, no. 1-2, pp. 138-145, 2003.

[2] B. Forood, B. T. Flatt, C. Chassaing, and A. K. Katritzky, "2Aminopyridine derivatives and combinatorial libraries thereof," United States Patent US 6458789 B1, Lion Bioscience AG, 2002.

[3] L. E. Kapinos and H. Sigel, "Acid-base and metal ion binding properties of pyridine-type ligands in aqueous solution: effect of ortho substituents and interrelation between complex stability and ligand basicity," Inorganica Chimica Acta, vol. 337, pp. 131$142,2002$.

[4] C. Yenikaya, M. Poyraz, M. Sarı, F. Demirci, H. Ilkimen, and O. Büyükgüngör, "Synthesis, characterization and biological evaluation of a novel $\mathrm{Cu}$ (II) complex with the mixed ligands 2,6pyridinedicarboxylic acid and 2-aminopyridine," Polyhedron, vol. 28, no. 16, pp. 3526-3532, 2009.

[5] M. Odabaşoğlu, O. Büyükgüngör, G. Turgut, A. Karadağ, E. Bulak, and P. Lönnecke, "Crystal structure, spectral and thermal properties of 2-aminopyridinium adipate monoadipic acid dihydrate," Journal of Molecular Structure, vol. 648, no. 1-2, pp. 133-138, 2003.

[6] K. Pavani and A. Ramanan, "Influence of 2-aminopyridine on the formation of molybdates under hydrothermal conditions," European Journal of Inorganic Chemistry, no. 15, pp. 3080-3087, 2005.

[7] B. Dojer, A. Pevec, P. Šegedin et al., "Cobalt(II) coordination compounds with acetate and 2-aminopyridine ligands: synthesis, characterization, structures and magnetic properties of two polymorphic forms," Inorganica Chimica Acta, vol. 363, no. 7, pp. 1343-1347, 2010.

[8] M. A. S. Goher and T. C. W. Mak, "Preparation and structural characterization of di- $\mu$-azido-bis[azido(2-aminopyridine)aquo]dicopper(II), $\left[\mathrm{Cu}\left(2 \text {-ampy) }\left(\mathrm{N}_{3}\right)_{2}\left(\mathrm{H}_{2} \mathrm{O}\right)\right]_{2}\right.$," Inorganica Chimica Acta, vol. 85, no. 2, pp. 117-122, 1984.

[9] B. Kozlevčar, N. Lah, D. Žlindra, I. Leban, and P. Šegedin, "Copper(II) benzoates and acetates with 2-aminopyridine," Acta Chimica Slovenica, vol. 48, no. 3, pp. 363-374, 2001.

[10] L. Li and F. Yuan, "Synthesis and structural characterization of the heteroleptic nickel 2-aminopyridine complex of (acac) $\left(\mathrm{CH}_{3} \mathrm{COO}\right) \mathrm{Ni}\left(2-\mathrm{NH}_{2} \mathrm{Py}\right)_{2}$," Synthesis and Reactivity in Inorganic, Metal-Organic, and Nano-Metal Chemistry, vol. 42, no. 2, pp. 205-208, 2012.

[11] K. Sakai, N. Akiyama, and M. Mizota, "Bis(2-aminopyridine)(2, 2' -bipyridine)-platinum(II) dinitrate dihydrate," Acta Crystallographica Section E: Structure Reports Online, vol. 59, no. 7, pp. m459-m461, 2003.

[12] M. M. Mashaly, "Synthesis and characterization of some new oxorhenium(V) complexes with annulene derivatives and their biological activities," Synthesis and Reactivity in Inorganic and Metal-Organic Chemistry, vol. 34, no. 1, pp. 115-144, 2004.

[13] S. Nieto, J. Pérez, L. Riera, V. Riera, and D. Miguel, "Metal complexes with two different hydrogen-bond donor ligands as anion hosts," Chemical Communications, no. 22, pp. 3279-3281, 2009.

[14] N. Lah, P. Šegedin, and I. Leban, "Crystal structures of two monomeric copper(II) carboxylates with 2-aminopyridine," Structural Chemistry, vol. 13, no. 3-4, pp. 357-360, 2002.

[15] N. Kanematsu, M. Ebihara, and T. Kawamura, "Preparation, structure and electrochemical behavior of dinuclear cyclooctadiene-chelated $\operatorname{Ir}(\mathrm{I})$ complexes with 2-aminopyridinato bridges," Inorganica Chimica Acta, vol. 292, no. 2, pp. 244-248, 1999.

[16] S. A. Al-Jibori, Q. K. A. Al-Jibori, H. Schmidt, K. Merzweiler, C. Wagner, and G. Hogarth, "Palladium(II) saccharinate (sac) and thiosaccharinate (tsac) complexes with 2-aminopyridine (2ampy), 2-acetylaminopyridine (2-aampy) and 2-acetylaminopyrimidine (2-aampym) co-ligands: X-ray crystal structures of trans- $\left[\mathrm{Pd}(\mathrm{sac})_{2}(\mathrm{ampy})_{2}\right]$ and solvatomorphs trans- $\left[\mathrm{Pd}(\mathrm{sac})_{2}(2-\right.$ aampy $\left.)_{2}\right] \cdot S\left(\mathrm{~S}=\mathrm{CHCl}_{3}\right.$, thf)," Inorganica Chimica Acta, vol. 402, pp. 69-74, 2013.

[17] P. L. Andreu, J. A. Cabeza, V. Riera, Y. Jeannin, and D. Miguel, "The different reactivity of 2-aminopyridines and 2pyridone with $\left[\mathrm{Ru}_{3}(\mathrm{CO})_{12}\right]$. $X$-ray crystal structure of $\left[\mathrm{Ru}_{3}(\mu\right.$ $\mathrm{H})\left(\mu_{3}\right.$-anpy $\left.)(\mathrm{CO})_{9}\right]$ (hanpy $=2$-anilinopyridine)," Journal of the Chemical Society, Dalton Transactions, no. 7, pp. 2201-2206, 1990. 
[18] S. Caglar, I. E. Aydemir, E. Adigüzel, B. Caglar, S. Demir, and O. Buyukgungor, "Four copper(II) diclofenac complexes with pyridine derivatives: synthesis, crystal structures, spectroscopic properties, thermal analysis and catechol oxidase activities," Inorganica Chimica Acta, vol. 408, pp. 131-138, 2013.

[19] E. Clot, J. Chen, D.-H. Lee et al., "Double geminal C-H activation and reversible $\alpha$-elimination in 2-aminopyridine iridium(III) complexes: the role of hydrides and solvent in flattening the free energy surface," Journal of the American Chemical Society, vol. 126, no. 28, pp. 8795-8804, 2004.

[20] B. Dojer, A. Pevec, M. Jagodič, M. Kristl, and M. Drofenik, "Three new cobalt(II) carboxylates with 2-, 3- and 4aminopyridine: syntheses, structures and magnetic properties," Inorganica Chimica Acta, vol. 383, pp. 98-104, 2012.

[21] A. Moghimi, S. M. Moosavi, D. Kordestani et al., "Pyridine-2,6bis(monothiocarboxylic) acid and 2-aminopyridine as building blocks of a novel proton transfer compound: solution and X-ray crystal structural studies," Journal of Molecular Structure, vol. 828, no. 1-3, pp. 38-45, 2007.

[22] J. H. K. Yip, Suwarno, and J. J. Vittal, "Syntheses and electronic spectroscopy of $\left[\mathrm{PtL}\left(\mathrm{L}^{\prime}\right)\right]\left[\mathrm{ClO}_{4}\right]$ complexes $(\mathrm{HL}=6$ phenyl-2,2'-bipyridine; $\mathrm{L}^{\prime}=$ pyridine, 4 -aminopyridine, 2aminopyridine, and 2,6-diaminopyridine)," Inorganic Chemistry, vol. 39, no. 16, pp. 3537-3543, 2000.

[23] F. A. Mautner, A. Egger, B. Sodin et al., "Two new azido bridging $\mathrm{Mn}(\mathrm{II}) 1 \mathrm{D}$ systems: synthesis and characterization of trans- $\left[\mathrm{Mn}\left(\mathrm{N}_{3}\right)_{2}(2 \text {-aminopyridine })_{2}\right]_{n}$ and trans- $\left[\mathrm{Mn}\left(\mathrm{N}_{3}\right)_{2}(4-\right.$ azidopyridine $\left.)_{2}\right]_{n}$," Journal of Molecular Structure, vol. 969, no. 1-3, pp. 192-196, 2010.

[24] L. Mei, L. S. Tai, J. Li, F. H. Tao, L. X. Liang, and Y. S. Zhong, "Synthesis and catalytic activity of DI- $\mu$-methoxo-bis[(2aminopyridine) (chloro)copper(II)] and m-xylylenediamine $\mathrm{Zn}(\mathrm{OAc})_{2}$," Russian Journal of Coordination Chemistry, vol. 37, no. 2, pp. 153-159, 2011.

[25] G. Sharma and A. K. Narula, "Synthesis and optoelectronic properties of three $\mathrm{Eu}(\mathrm{III})$-dipicolinate complexes based on $\alpha$-picolinic acid, 2-aminopyridine and 2-hydroxypyridine as secondary ligands," Journal of Materials Science: Materials in Electronics, vol. 26, no. 2, pp. 1009-1017, 2015.

[26] H.-L. Sun, Z.-M. Wang, and S. Gao, "Synthesis, crystal structures, and magnetism of cobalt coordination polymers based on dicyanamide and pyrazine-dioxide derivatives," Inorganic Chemistry, vol. 44, no. 7, pp. 2169-2176, 2005.

[27] A. Mohamadou, G. A. van Albada, H. Kooijman, B. Wieczorek, A. L. Spek, and J. Reedijk, "The binding mode of the ambidentate ligand dicyanamide to transition metal ions can be tuned by bisimidazoline ligands with $\mathrm{H}$-bonding donor property at the rear side of the ligand," New Journal of Chemistry, vol. 27, no. 6, pp. 983-988, 2003.

[28] K. S. Murray, S. R. Batten, B. Moubaraki, D. J. Price, and R. Robson, "Molecular magnetism in manganese dicyanamide extended network structures," Molecular Crystals and Liquid Crystals Science and Technology Section A: Molecular Crystals and Liquid Crystals, vol. 335, no. 1, pp. 313-322, 1999.

[29] W.-Z. Shen, X.-Y. Chen, P. Cheng, D.-Z. Liao, S.-P. Yan, and Z.-H. Jiang, "Cobalt(II) complexes with dicyanamide-from binuclear entities to chains," Zeitschrift für Anorganische und Allgemeine Chemie, vol. 629, no. 14, pp. 2591-2595, 2003.

[30] L. Zheng, "Synthesis, crystal structures, and magnetic properties of ternary M(II)-dicyanamide-hydroxypyridine complexes," Journal of Inorganic Chemistry, vol. 2013, Article ID 206589, 10 pages, 2013.
[31] Z.-W. Li, P.-P. Yang, X.-L. Wang, and L.-C. Li, "Syntheses, structures, and magnetic properties of two 1-D dicyanamide manganese(III) complexes with Schiff-base ligands," Journal of Coordination Chemistry, vol. 63, no. 9, pp. 1538-1545, 2010.

[32] J. Luo, L. Qiu, B. Liu, X. Zhang, F. Yang, and L. Cui, "Synthesis, structure and magnetic properties of two cobalt(II) dicyanamide (dca) complexes with heterocyclic nitrogen donors tetra(2-pyridyl)pyrazine (tppz) and 2,4,6-Tri(2pyridyl)-1,3,5-triazine (tptz): $\left[\mathrm{Co}_{2}(\mathrm{tppz})(\mathrm{dca})_{4}\right] \cdot \mathrm{CH}_{3} \mathrm{CN}$ and $\left[\mathrm{Co}(\mathrm{tptz})(\mathrm{dca})\left(\mathrm{H}_{2} \mathrm{O}\right)\right](\mathrm{dca})$, , Chinese Journal of Chemistry, vol. 30, no. 3, pp. 522-528, 2012.

[33] H. Gopinathan, N. Komathi, and M. N. Arumugham, "Synthesis, structure, DNA binding, cleavage and biological activity of cobalt (III) complexes derived from triethylenetetramine and 1,10 phenanthroline ligands," Inorganica Chimica Acta, vol. 416, pp. 93-101, 2014.

[34] M. O. Agwara, P. T. Ndifon, N. B. Ndosiri, A. G. Paboudam, D. M. Yufanyi, and A. Mohamadou, "Synthesis, characterisation and antimicrobial activities of cobalt(II), copper(II) and zinc(II) mixed-ligand complexes containing 1,10-phenanthroline and 2,2' -bipyridine," Bulletin of the Chemical Society of Ethiopia, vol. 24, no. 3, pp. 383-389, 2010.

[35] M. M. Mashaly, Z. H. Abd-Elwahab, and A. A. Faheim, "Preparation, spectral characterization and antimicrobial activities of Schiff base complexes derived from 4-aminoantipyrine. Mixed ligand complexes with 2-aminopyridine, 8-hydroxyquinoline and oxalic acid and their pyrolytical products," Journal of the Chinese Chemical Society, vol. 51, no. 5, pp. 901-915, 2004.

[36] S. Saha, A. Sasmal, C. R. Choudhury et al., "Synthesis, crystal structure, antimicrobial screening and density functional theory calculation of nickel(II), cobalt(II) and zinc(II) mononuclear Schiff base complexes," Inorganica Chimica Acta, vol. 425, pp. 211-220, 2015.

[37] Bruker, APEX2, SAINT-Plus and XPREP, Bruker AXS, Madison, Wis, USA, 2004.

[38] G. M. Sheldrick, "A short history of SHELX," Acta Crystallographica Section A, vol. 64, no. 1, pp. 112-122, 2008.

[39] A. Colette, A. M. Ondoh, D. M. Yufanyi, and D. S. Yanick Gaelle, "Synthesis, crystal structure and antimicrobial properties of an anhydrous copper(II) complex of pyridine-2-carboxylic acid," International Journal of Chemistry, vol. 7, no. 1, pp. 10-20, 2015.

[40] E. N. Nfor, P. F. Asobo, J. Nenwa et al., "Nickel (II) and iron (II) complexes with azole derivatives: synthesis, crystal structures and antifungal activities," International Journal of Inorganic Chemistry, vol. 2013, Article ID 987574, 6 pages, 2013. 

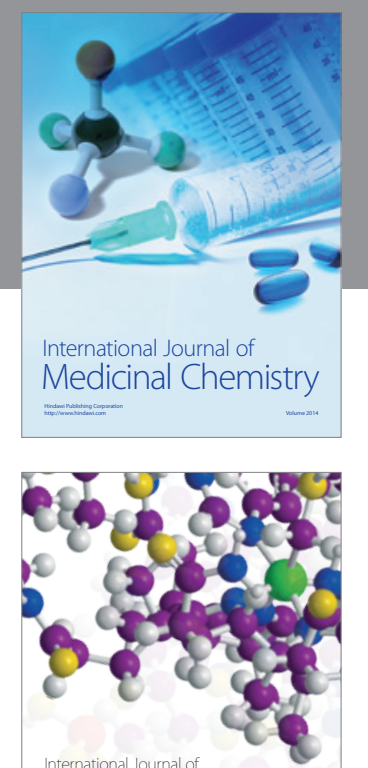

\section{Carbohydrate} Chemistry

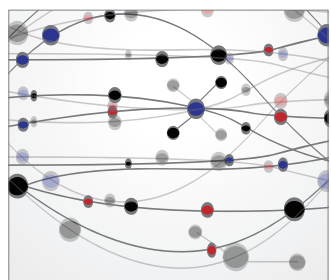

The Scientific World Journal
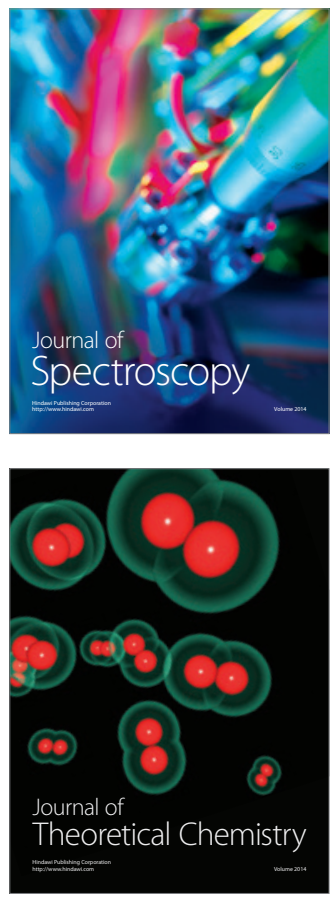
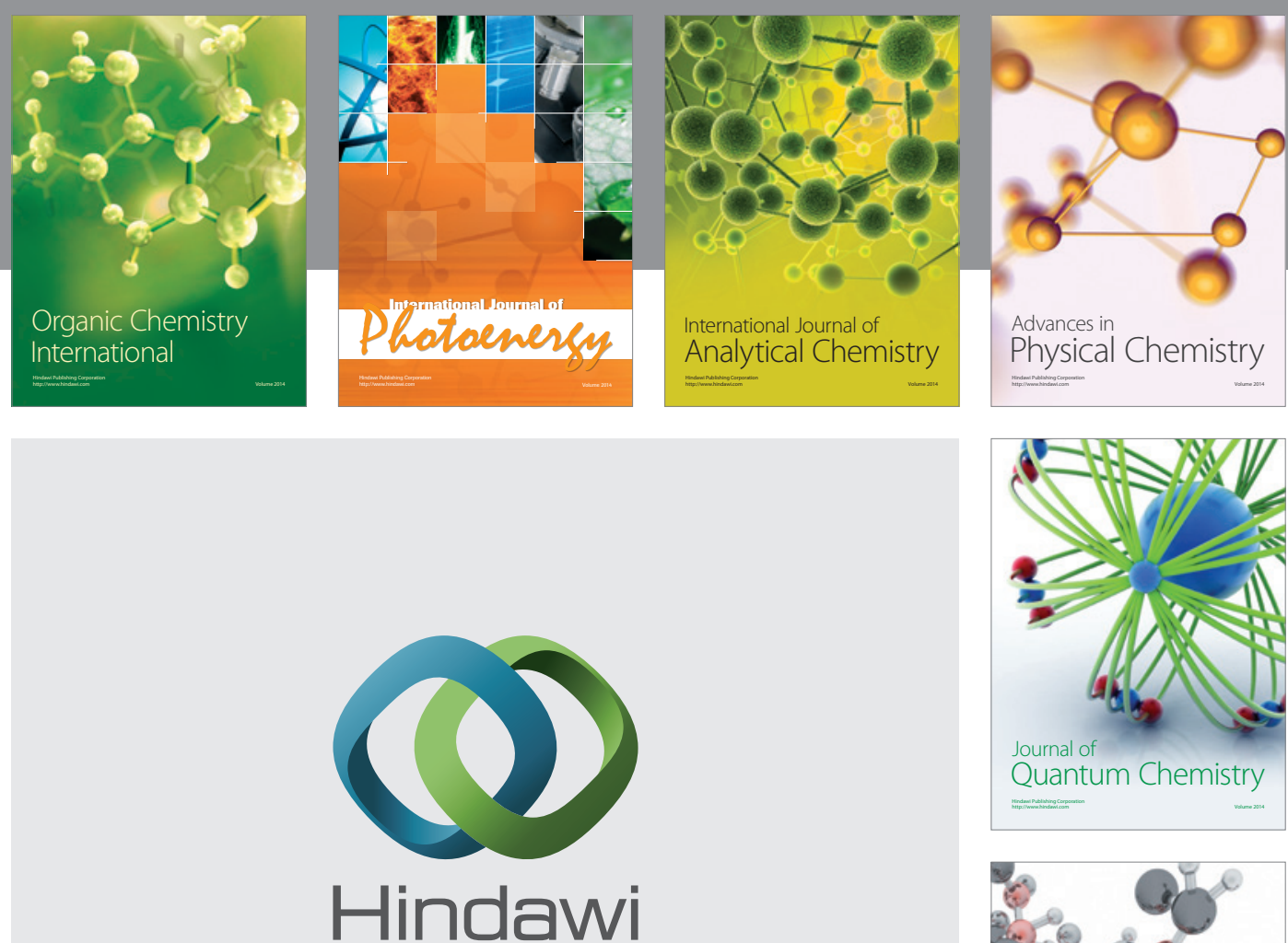

Submit your manuscripts at

http://www.hindawi.com

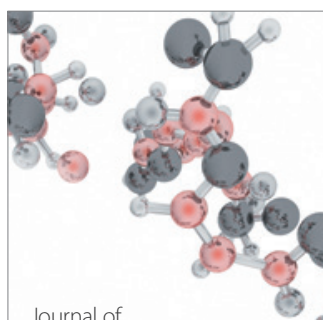

Analytical Methods

in Chemistry

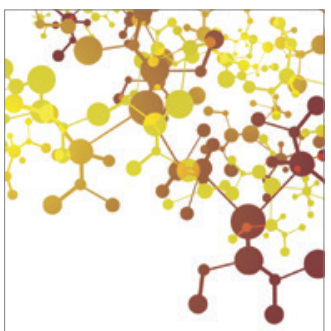

Journal of

Applied Chemistry

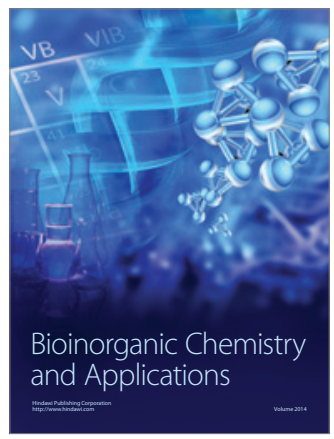

Inorganic Chemistry
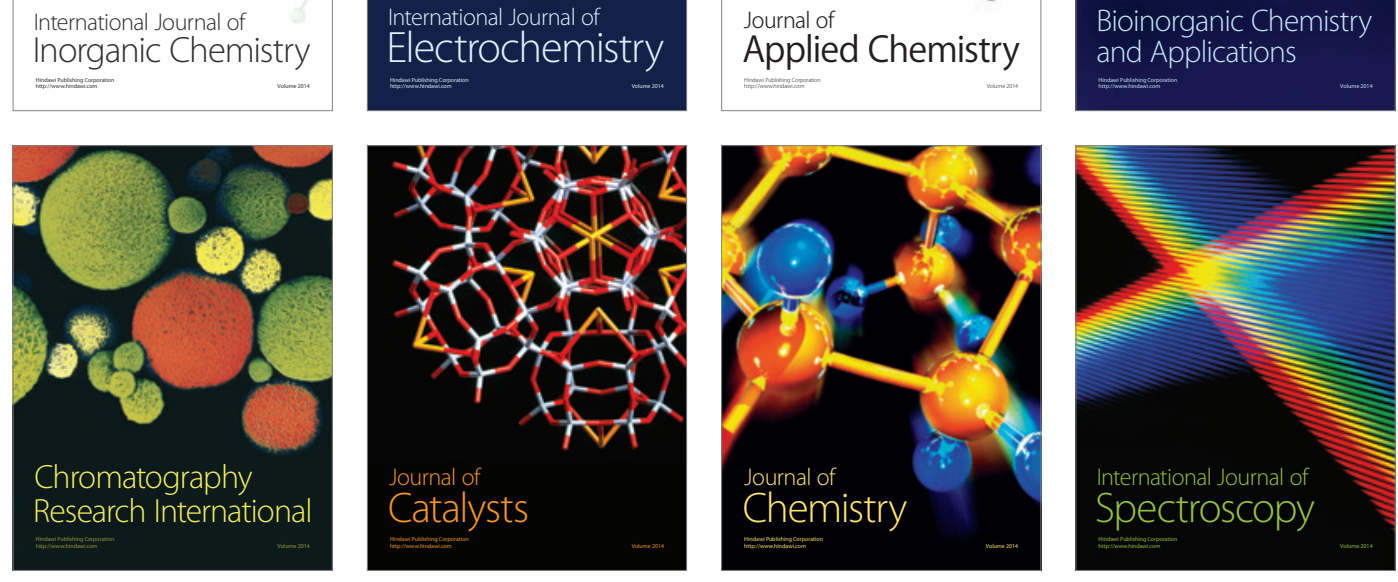